\title{
Translation and Cultural Adaptation of PROactive Instruments for COPD in French and Influence of Weather and Pollution on Its Difficulty Score
}

This article was published in the following Dove Press journal: International Journal of Chronic Obstructive Pulmonary Disease

Trija Vaidya $\mathbb{B}^{\prime}$

Véronique Thomas-Ollivier ${ }^{2}$

François Hug ${ }^{2,3}$

Alain Bernady $\mathbb{1 D}^{4}$

Camille Le Blanc ${ }^{5}$

Claire de Bisschop (iD) ${ }^{1}$

Arnaud Chambellan ${ }^{2,6}$

'Laboratory MOVE (EA63 I4), Université de Poitiers, Faculty of Sport Sciences,

Poitiers, France; ${ }^{2}$ Faculty of Sport Sciences,

Movement-Interactions-Performance, MIP, EA 4334, Université de Nantes, Nantes F-4000, France; ${ }^{3}$ Institut Universitaire de France (IUF), Paris, France; ${ }^{4}$ Toki-Eder Centre Médical Cardio-Respiratoire,

Cambo-Les-Bains, France; ${ }^{5}$ Physical Medicine and Rehabilitation Department, University Hospital of Nantes, Nantes, France; ' 'L'institut du Thorax, Laboratory MIP, UNIV Nantes, University Hospital of Nantes, Nantes, France
Correspondence: Arnaud Chambellan Explorations fonctionnelles, l'institut du thorax, $\mathrm{CHU}$ de Nantes, Bd Jacques Monod, Nantes Cedex I 44093, France

Tel +33240 I65 5II

$\mathrm{Fax}+33240165391$

Email arnaud.chambellan@chu-nantes.fr
Introduction: The recently developed daily and clinical visit PROactive physical activity in COPD (PPAC) instruments are hybrid tools to objectively quantify the level of physical activity and the difficulties experienced in everyday life. Our aim was to translate these instruments for the French-speaking chronic obstructive pulmonary disease (COPD) community worldwide and evaluate the influence of weather and pollution on difficulty score.

Methods: The translation procedure was conducted following the guidelines for crosscultural adaptation process. The translated clinical visit (C-PPAC) was tested among COPD patients in France. A retest was conducted after an interval of at least 2 weeks. The C-PPAC difficulty score was then tested to see how sensitive it was to the influence of weather and outdoor pollution.

Results: One hundred and seventeen COPD patients (age 65 \pm 9 years; FEV1: $51 \pm 20 \%$ ) from 9 regions in France were included. The French version of C-PPAC was found comprehensible by the patients with an average score of $4.8 / 5$ on a Likert-scale. It showed good internal consistency with Cronbach's $\alpha>0.90$ and a good test retest reliability with an intraclass correlation coefficient of $\geq 0.80$. The difficulty score was negatively correlated with duration of daylight $(\rho=-0.266$; $p<0.01$ ) and influenced by the intensity of rainfall (light vs. heavy rainfall: $68 \pm 16$ vs. $76 \pm 14$ respectively, $p=0.045$ ). The score was lower in patients receiving long term oxygen therapy (60 \pm 15 vs. $71 \pm 15, p<0.01$ ), but not correlated with the pollution indices.

Conclusion: The French versions of the questionnaires of the PPAC instruments are accepted and comprehensible to COPD patients. The difficulty score of C-PPAC is sensitive to duration of daylight and rainfall. Such weather factors must be taken into consideration when evaluating the physical activity behavior using these tools in COPD

Keywords: COPD, physical activity, questionnaire, reliability

\section{Introduction}

The Physical Activity (PA) behavior is an important outcome in patients with chronic obstructive pulmonary disease (COPD). Following numerous studies, this variable has paved its way as a significant prognostic marker in the field of research in COPD. There are consistent evidences that COPD patients show lower levels of PA when compared to their healthy peers. ${ }^{1,2}$ Higher levels of PA have also been associated with lower risk of exacerbations, hospitalization as well as mortality in COPD. ${ }^{3}$

The use of activity monitors is known to have a great value in measuring the amount and intensity of PA. ${ }^{4}$ The subjective method such as the self-reports of PA 
perception by the patient has also widely been used with the availability of numerous questionnaires. ${ }^{5,6}$ Although these capture the perception of a patient in a wide variety of situations, they have been known to either overestimate or underestimate their PA levels when compared to accelerometers. ${ }^{7}$ Thus, emphasizing that either of the method is valuable in its own way, the combination of both would rather be a topical solution. ${ }^{8}$

An important aspect in the measure of PA among COPD patients is to have the proper representation of how the patient perceives the daily engagement in PA. This representation covers many dimensions such as social, cultural as well as behavioral psychology which influence PA independently of the disease. ${ }^{9}$ The disease further adds on to the reduction of engaging in PA. The PROactive Physical Activity in COPD (PPAC) instruments, C-PPAC (clinical visit) and D-PPAC (daily) developed by the PROactive consortium are hybrid tools that respond to this need of global representation and give detailed feedback regarding patient's PA experience. These tools give a qualitative assessment via a patientreported outcome (PRO) questionnaire as well as a quantitative analysis via an activity monitor, giving two distinct scores, amount and difficulty. ${ }^{10}$ Higher scores indicate higher engagement and tolerance in PA. This global and disease-specific approach of PA remains very attractive and appropriate in the context of the fight against a sedentary lifestyle in the COPD population worldwide.

It is important to evaluate and educate the Frenchspeaking community of COPD patients as they belong to a large linguistic group throughout the world, representing about 300 million people and the fifth most widely spoken language worldwide. ${ }^{11}$ As the prevalence of COPD has dramatically increased, especially in sub-Saharan Africa, it is expected to occur in most French-speaking African countries, that to say more than half of the Frenchspeaking community worldwide. ${ }^{12}$

There are only a few questionnaires assessing PA within the French community, ${ }^{13}$ among which, few were originally developed in French, ${ }^{14-17}$ and even fewer in translated versions. ${ }^{18-21}$ The French 9-item questionnaire by J. Ricci and L. Gagnon (University of Montreal) that categorizes a person's profile into inactive, active or very active is easy to use and though broadly distributed, has no scientific validation. Most of these are targeted to general or elderly population. An evaluation specific to COPD, the DIsability RElated to COPD Tool (DIRECT), evaluates this disability in daily life with some similarities to PROactive tools but does not measure the quantitative level of PA. ${ }^{22}$ Thus, there is a need for a proper evaluation of PA to improve the content of personalized medicine including behavioral education towards improvement and maintenance of a regular level of PA.

The weather has also been known to play an important role in determining PA among these patients. A $10^{\circ} \mathrm{C}$ increase in temperature was known to translate to an increase of about 316 steps per day and rainfall of $10 \mathrm{~mm}$ to 175 fewer steps. ${ }^{23}$ A decline in daily steps has also been observed with a decline in temperature. ${ }^{24,25}$ Similarly, when compared with atmospheric pollution, a decrease in PA has been associated with higher ozone $\left(\mathrm{O}_{3}\right)$ levels and higher particulate matter $\left.\left(\mathrm{PM}_{10}\right)\right)^{26}$ Hence, the primary aim of this study was to translate and evaluate the questionnaires in the PROactive instruments among the French-speaking COPD patients. The secondary aim was to evaluate the influence of weather and outdoor pollution on difficulty score as a goal to understand if environment is a confounding factor.

\section{Materials and Methods Cross-Cultural Translation Procedure}

The C- and D-PPAC instruments were translated following the 6 stages detailed in the guidelines for cross-cultural adaptation of self-report measures by Beatonet $\mathrm{al}^{27}$ (Supplementary material). Both C and D-PPAC consist of similar and common items with former containing five questions more. Since C-PPAC evaluated weekly PA, only this was taken into account for evaluation in patients, which constituted the fifth stage of the translation process. The sixth stage consisted of submission of translated versions to the developers of PROactive instruments for agreement (Pr. T. Troosters, scientific coordinator of the PROactive consortium). This process led to few final adjustments, the details of which as well as the final French versions of C- and D-PPAC are given in supple mentary material.

\section{Subjects}

COPD patients were recruited from 9 regions in France between May 2017 and May 2018. They were recruited either during an evaluation of pulmonary rehabilitation in 2 centers (University Hospital in Nantes, and the Toki Eder Center in Cambo-les-Bains) which constituted 54\% of total patients included, or from the "Federation Française des Associations et Amicales d'Insuffisants 
Respiratoires" (FFAAIR), which brings together patients suffering from chronic respiratory diseases in France. ${ }^{28}$ All patients gave their verbal consent to participate in this study approved by the local ethical committee board, Groupe Nantais d'Ethique dans le Domaine de la Santé (GNEDS), according to the French Jardé's law (decree ${ }^{\circ}$ 2016-1537, November the $\left.16^{\text {th }}, 2017\right) .{ }^{29}$ The patients at the centers completed paper version of C-PPAC during their consultation. The patients recruited from FFAAIR completed an electronic version sent to them via a secured web platform. No activity monitor, was considered in this study as the main purpose of this study was to evaluate the translated versions and give insight about the effect of weather conditions and pollution on difficulty score that can modulate its interpretation. Hence, only the difficulty score was taken into consideration for analysis. Apart from this context, it should be remembered that, in practice, the questionnaire is not to be administered without an activity monitor which allows to calculate the amount and total scores.

\section{Comprehensibility, Test-Retest Reliability}

The comprehensibility of translated questions was evaluated by a 5-point Likert scale (Supplementary material). This scale evaluated the comprehensibility of each question along with its response items, giving a complete picture on the understanding of the questions as well as the choice of responses given.

COPD patients from centers refilled the questionnaire in a separate week with an interval of at least two weeks for retest evaluation. To ensure similarities of both periods, a separate 5-point Likert scale was added at the beginning of questionnaire. This gave an insight on any unusual situation related to atmospheric condition, family and other health issues that could have affected the PA experience of the patient in between. Only patients with a maximum difference of 2 points in this Likert scale were included in the analysis for test-retest reliability.

\section{Weather Conditions, Atmospheric Pollution and Geographical Localization}

The daily weather variables were obtained for each area from "Météo France." The main atmospheric pollutants (ATMO index) were obtained from the federation of air quality monitoring associations "Atmo Franc Details are given in the supplementary material. For the geographical localization, the patients were categorized into living in north or south and living near the coast or in center of France.

\section{Statistical Analysis}

All results are presented as mean \pm standard deviation (SD) or percentages. Comparison between groups was done by independent $t$ test in case of normality of distribution of values, otherwise with the Wilcoxon test. Only patients who completely the questionnaire were analyzed. The internal consistency of the questionnaire was assessed using Cronbach's $\alpha$ coefficient. The test-retest reliability was evaluated using intraclass correlation coefficient (ICC) for agreement. The duration of daylight was calculated using a given formula (Supplementary material).

The influence of weather, and ATMO index on the difficulty score was measured using the Spearman correlation coefficient rho. All the statistical analyses were performed using SigmaPlot 14.0 and IBM SPSS Statistics 20 (SPSS Inc., Chicago, IL, USA). The statistical significance level was fixed at a $p$-value of 0.05 .

\section{Results}

A total of 117 patients submitted a complete C-PPAC questionnaire. The baseline characteristics of these patients are given in Table 1.

\section{Comprehensibility}

The Likert scale evaluation of the comprehensibility of each question was complete in 101 patients, with an average score of $4.8 \pm 0.6$ ( 0 being "not at all clear" and 5 being "absolutely clear"). Questions 1 and 2 from the "amount" score were diversely appreciated reaching a Likert $5 / 5$ in $76 \%$ and $81 \%$ respectively, whereas all the others were above $85 \%$ (Figure 1). Although well understood, the first

Table I Baseline Characteristics of the Patients

\begin{tabular}{|c|c|}
\hline $\mathbf{N}$ & 117 \\
\hline Male/Female, n (\%) & $71(6 I) / 46$ (39) \\
\hline Age, year & $65 \pm 9$ \\
\hline BMI, kg.m ${ }^{-2}$ & $25.3 \pm 5.8$ \\
\hline LTOT, n (\%) & $26(22)$ \\
\hline FEV,$\%$ predicted* & $51 \pm 20$ \\
\hline GOLD I/2/3/4, n (\%)* & $5(4) / 27(23) / 21(18) / 9(8)$ \\
\hline $\mathrm{FEV}_{1} / \mathrm{FVC} \% *$ & $47 \pm 13.5$ \\
\hline
\end{tabular}

Notes: Data are presented as mean \pm SD unless otherwise indicated. *The available data are for $n=62$.

Abbreviations: $\mathrm{SD}=$ standard deviation; $\mathrm{BMI}=$ body mass index; $\mathrm{LTOT}=$ long

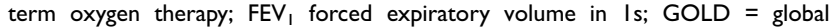
initiative for chronic obstructive lung disease; FVC = forced vital capacity. 


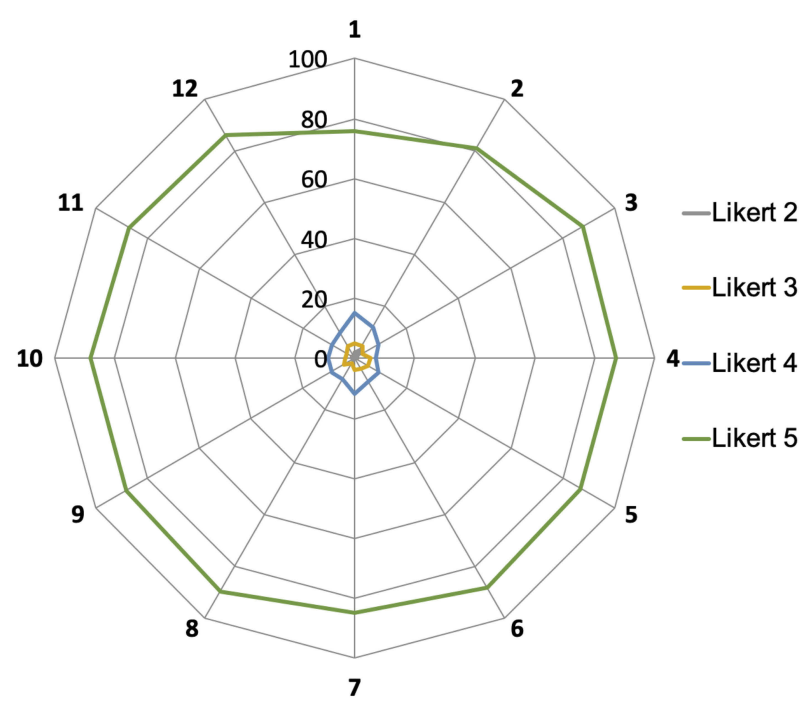

Figure I Comprehensibility of the C-PPAC questionnaire expressed in Likert scores for the 12 questions. Radar chart representing every Likert category from 0 to 5,0 being "not at all clear" to 5 being "absolutely clear" (the percentage of each Likert category is presented on the $y$-axis; Likert 0 and I were not visible due to the presence of $<5 \%$ of the patients).

question regarding the average walk done in a week, showed some uncertainty among few, in choosing the appropriate response item. The patients who walked only for few days, found it difficult to calculate the average duration of walk done for a week (Supplementary $\underline{\text { material)}}$.

\section{Reliability}

Thirty-one out of 35 who filled the C-PPAC twice in an average of a 2-week interval met the criteria for analysis of retest. A strong internal consistency was found with a Cronbach's $\alpha>0.90$. The questionnaire obtained a good test retest reliability with an ICC $\geq 0.80$ for difficulty score.

\section{Influence of Oxygen Status, Weather Condition, Pollution and Geographical Localization on the Difficulty Score}

The average difficulty score obtained in 117 patients was $69 \pm 16$. A significant difference was found between the

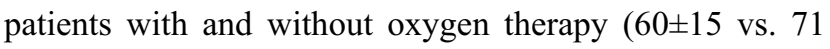
$\pm 15, p=0.002$ ) (Figure 2A).

The four seasons, winter, spring, summer and autumn did not have any influence ( $p=0.234$, ANOVA), but a negative correlation was observed between the duration of daylight and the difficulty score $(\rho=-0.266, p=0.004)$. When patients where stratified depending on the intensity of rainfall (light to moderate vs. heavy) during the week, there was a significant difference in the scores $(68 \pm 16$ vs. $76 \pm 14, p=0.045$ ) (Figure 2B). There was a tendency for the score to decrease with higher temperature $(\rho=-0.150$, $p=0.107)$. There was no correlation between the score and the ATMO index $(\rho=-0.088, p=0.345)$, with a mean ATMO index of $3.6 \pm 0.5$ (meaning good conditions).

There was no influence of geographical localization among the 117 patients (92 lived in the north and 25 in the south of France). There was a tendency for patients living near the coast to have a slightly higher score compared to those living in the center $(70 \pm 16$ vs. $65 \pm 14$, $p=0.088)$. They were however not corrected for severity. (This data was out of the purpose of this study and not available for some of the patients.)
A

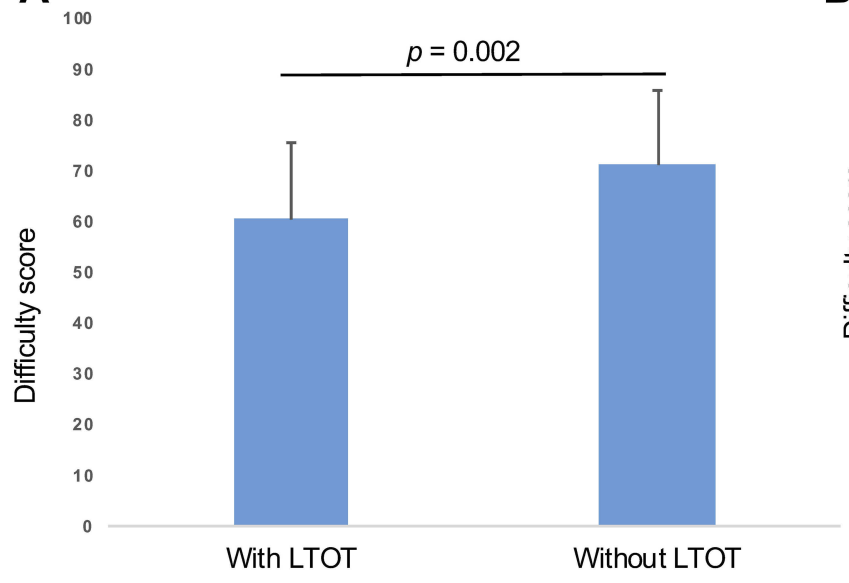

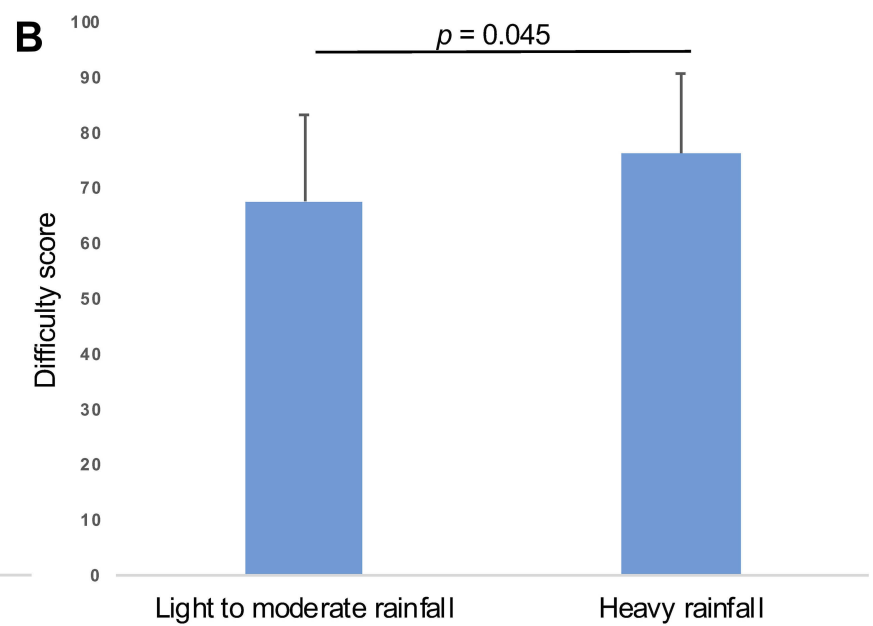

Figure 2 (A) Difficulty score of the C-PPAC questionnaire in patients with and without LTOT. LTOT = long term oxygen therapy. (B) Difficulty score of the C-PPAC questionnaire according to the influence of rainfall. 
Figure 3 shows the dispersion of recruited COPD patients and the weather parameters in areas concerned.

\section{Discussion}

The purpose of this study was to translate and provide an adapted French version of the questionnaires of PPAC instruments in COPD patients for French population. Our result showed the translated version to be well understood and accepted by COPD patients in France. Hence, the translated versions could be used for the ultimate validation of the questionnaires by using activity monitor. To the best of our knowledge, these are the first PA assessment instruments that cover both subjective and objective assessment and the first of its kind now available in French language.

The questionnaires to assess PA in general population have existed for a long time such as the Baecke's PA questionnaire for young adults ${ }^{30}$ that focused on three axes; work, sports and leisure activities, whose sum gave global PA score. The French version of this questionnaire was made available by Bigardet $\mathrm{al}^{31}$ and a modified version by
Volet $\mathrm{al}^{18} \mathrm{~A}$ modified version was validated among elderly population, ${ }^{32}$ but does not exist in French. A reliable and feasible interviewer administered questionnaire to assess relationship between PA and diabetes with a 1-year recall in Native Americans is also available in a French selfadministered version. ${ }^{19,33}$ Similarly, the International Physical Activity Questionnaire (IPAQ), designed for adults, was also validated in French. ${ }^{20,21}$ Some of the French questionnaires assessing PA such the Saint-Etienne physical activity questionnaire (QAPSE) ${ }^{14}$ the Physical Activity score of Dijon (SAPD), ${ }^{15}$ the Physical activity questionnaire for the elderly (QAPPA) ${ }^{16}$ and the Quantification of PA (QUANTAP) ${ }^{17}$ are however, targeted for healthy elderly population. Only few have been validated in COPD; the Modified version of Baecke questionnaire, $^{34}$ IPAQ $^{35}$ and QUANTAP system. ${ }^{36}$ A COPD specific 12-items questionnaire DIRECT developed in French, assessed the perception of difficulty related to the disease on daily life. ${ }^{22}$ Although similar to PROactive tools in terms of assessing difficulty level regarding PA, it
A

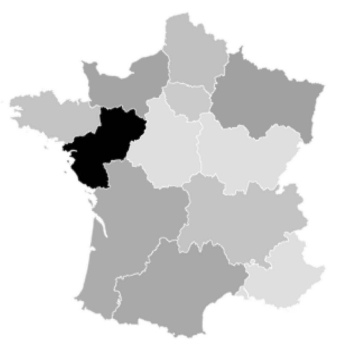

Powered by Bing
O DSAT Editor, DSAT for MSF, GeoNames, Navteq, Wikipedia

D

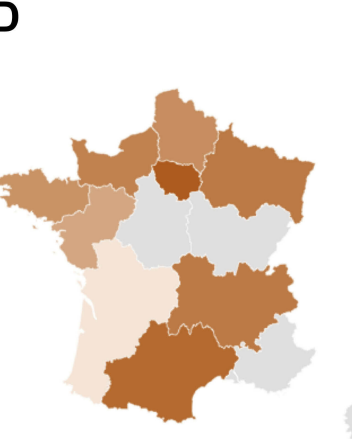

Powered by Bing

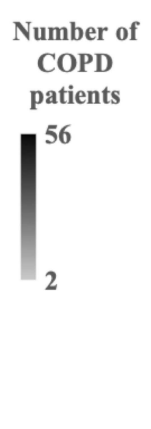

B
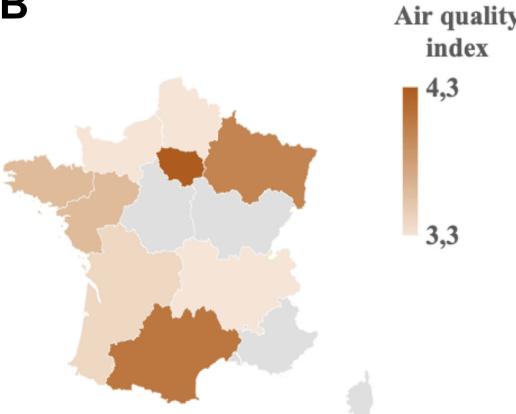
index
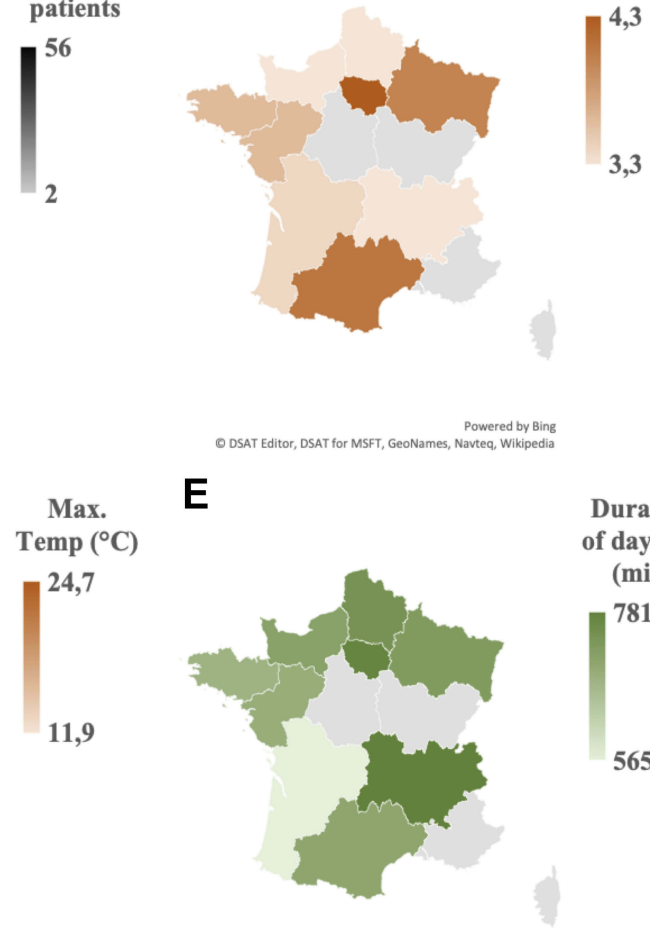

E

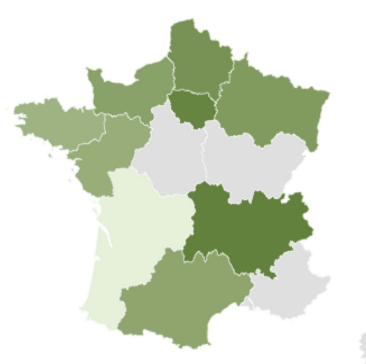

Powered by Bing
C

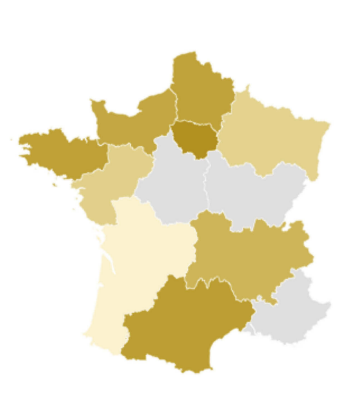

Min. Temp

$\left({ }^{\circ} \mathrm{C}\right)$

14,4

5,8

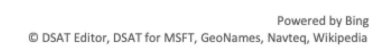

$\mathbf{F}$

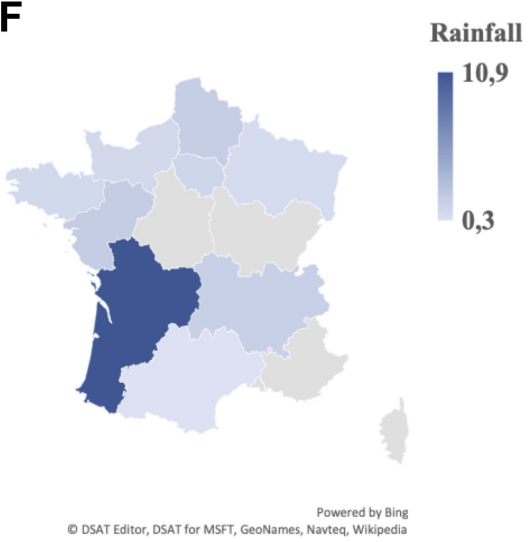

Figure 3 Regional dispersion of variables in France. (A) Number of COPD patients. (B) Air quality index from $0=$ very good to $10=$ very bad quality). (C) Minimum temperature $\left({ }^{\circ} \mathrm{C}\right)$. (D) Maximum temperature $\left({ }^{\circ} \mathrm{C}\right)$. (E) Duration of daylight $(\mathrm{min})$. (F) Intensity of rainfall (mm). All variables were obtained on a daily basis measure and expressed as mean week-value, except for $(\mathbf{A})$. 
lacks the objective evaluation of quantifying PA. This makes the PROactive tools more advantageous.

The patients in our study were recruited from rural and urban areas, globally from middle class with a minimum level of education. Although they were not each tested for a reading level, there was no confusion related to the questions. The slightly lower Likert score for the first question could be explained by the confusion of calculating amount of average walk done per day for patients who walked only few days per week. The remarks for this question are however directed to the original concept of the question. This question being related to the number of steps registered by the activity monitor, underlines the importance of its use.

When analyzing the factors influencing difficulty score, our study showed that the patients on LTOT had lower difficulty score, which could be expected as these patients are known to engage less in PA and would experience more difficulty during any PA. This could mean that the score could reflect psychometric property of a PA behavior among the patients who are more advanced in the disease stage.

The evidence of geographical influence among French adults and elderly population has shown to exist with people living in Southern France having higher level of PA than the ones living in North. ${ }^{37}$ Similarly, an independent association between proximity to coast and higher levels of PA was found among habitants of New South Wales. ${ }^{38}$ In both these studies, the assessment of PA was done by self-report methods. Our study, since focused mainly on difficulty score did not show such associations. This could also be explained by non-homogeneity in the groups, North vs. South (92 vs. 25 ) and proximity to coast vs. inland ( 85 vs. 32 ). A seasonal and climatic influence on PA among COPD patients taken from two different geographic regions with important climatic variations; Belgium and Brazil was recently reported. A significant reduction in activity time was seen during winter. There was however no influence from rainfall. ${ }^{24}$ In our study, there was a significant difference in difficulty scores between the patients who experienced light and heavy rainfall. The possible influence of extrinsic factor as rainfall may be considered on the perception of difficulty. The negative correlation with the duration of daylight observed in our study could be explained by the assumption that COPD patients tend to go outdoors during seasons with longer durations of daylight, exposing them to environmentrelated difficulty. The difficulty score in our study however did not show any significant association with the pollution
ATMO index as it was seen in the study by Alahmari et al. where the reduction of PA was observed with the increment of atmospheric pollution levels. ${ }^{26}$ The main reason is probably related to the good quality of the air that was recorded throughout the 847 patient-days in our study, with only less than $2 \%$ of days with poor air quality.

A systematic review of data from 8 different countries, including France, also showed a decrease in PA during the winter season in the general population. ${ }^{39}$ Absence of seasonal associations in our study could again be explained by non-homogeneity in the groups or that this particular tool is not precise enough to detect climate related influence. Associations between a reduction of PA with either a reduction in temperature or an increase in rainfall have been presented when assessed objectively, which underline the importance of using combined subjective and quantitative approaches. ${ }^{23,25}$

The significance of a threshold of change in the scores that can be proposed as minimal important difference in context of pulmonary rehabilitation and other behavioral intervention is yet to be determined. These instruments have been and are being explored in studies that investigate the effect of bronchodilators with or without behavioral ${ }^{40}$ or PA interventions. ${ }^{41}$ Our study confirms the reliability of using these instruments among COPD patients in the French population. The use of these hybrid tools may however be limited by the cost of activity monitors and their application during short clinical visits. Nevertheless, the combination of objective information as well as patient reported information should be considered an innovation in the patient reported outcome field. These tools provide unique insight into the mechanism why an intervention is perceived by patients as beneficial. Some interventions may alter the experienced amount of PA, whereas others may impact on the experienced difficulties. ${ }^{41}$

This study had some limitations. Firstly, the evaluation of questionnaires of PPAC instruments in French was done without activity monitors. This choice was made in conjunction with the main objective of study, the validation of the French version. However, as indicated above, the analysis could be enriched by using an activity monitor. Secondly, the number of patients recruited in different regions was not equally distributed with the sample size being quite low and lacked a wider range of COPD spectrum. This could explain the lack of correlations in the analysis of the weather variables and thus the results must be interpreted carefully. Thirdly, the study is cross-sectional in nature and therefore the correlations between questionnaire scores and climate 
should be interpreted with caution. Future studies could try to confirm these relations with repeated measures within a subject in different climatologic conditions. Furthermore, comprehension evaluation of these tools by the French community notably in Canada, sub-Saharan Africa could be interesting.

\section{Conclusion}

The French versions of the questionnaires of PPAC instruments are well accepted by COPD patients and show good reliability. These translated versions could be used for the validation of the questionnaires by including activity monitor as required. The difficulty score is sensitive to weather conditions, which should be monitored for a proper interpretation of the score. These instruments are important to consider in future studies on COPD, notably in French-speaking community worldwide to assess the level and impact of PA in daily life and the weight of cultural cross links with a careful attention to influence of weather. The value and sensitivity of the scores to any kind of change still need to be clarified in the follow up of COPD patients. These tools will be of great interest to capture long-term adherence and behavior modification towards PA engagement in daily living, notably in the perspective to measure the effects of new healthcare approaches such as telemedicine in pulmonary rehabilitation.

\section{Acknowledgments}

The authors wish to thank patients from the French association of respiratory insufficiency FFAAIR for their important contribution in evaluation of comprehension and cultural adaptation of the French version of $\mathrm{C}$ and D-PPAC. We thank Professor Frédéric Costes (University Hospital of Clermont Ferrand) for his support on the inclusion of patients. We thank Françoise Wheddon (F.W.), Emilie Fowell (E.F.) and Rosemary Andreu (R.A.) for their participation as translators. We thank Professor Thierry Troosters (Department of Rehabilitation Sciences, Faculty of Kinesiology and Rehabilitation Sciences and Respiratory Division, University Hospital Leuven, Leuven, Belgium), on behalf of the PROactive consortium, for his contribution in the last process of validation of the final versions of the PPAC and for critically reviewing the manuscript.

\section{Disclosure}

The authors report no conflicts of interest in this work.

\section{References}

1. Troosters T, Sciurba F, Battaglia S, et al. Physical inactivity in patients with COPD, a controlled multi-center pilot-study. Respir Med. 2010;104(7):1005-1011. doi:10.1016/j.rmed.2010.01.012

2. Vorrink SNW, Kort HSM, Troosters T, Lammers J-WJ. Level of daily physical activity in individuals with COPD compared with healthy controls. Respir Res. 2011;12:33. doi:10.1186/1465-9921-12-33

3. Gimeno-Santos E, Frei A, Steurer-Stey C, et al. Determinants and outcomes of physical activity in patients with COPD: a systematic review. Thorax. 2014;69(8):731-739. doi:10.1136/thoraxjnl-2013204763

4. Van Remoortel H, Giavedoni S, Raste Y, et al. Validity of activity monitors in health and chronic disease: a systematic review. Int J Behav Nutr Phys Act. 2012;9:84. doi:10.1186/1479-5868-9-84

5. Williams K, Frei A, Vetsch A, Dobbels F, Puhan MA, Rüdell K. Patient-reported physical activity questionnaires: a systematic review of content and format. Health Qual Life Outcomes. 2012;10:28. doi:10.1186/1477-7525-10-28

6. Liao S-Y, Benzo R, Ries AL, Soler X. Physical activity monitoring in patients with chronic obstructive pulmonary disease. Chronic Obstr Pulm Dis. 2014;1(2):155-165. doi:10.15326/jcopdf.1.2.2014.0131

7. Prince SA, Adamo KB, Hamel ME, Hardt J, Connor Gorber S, Tremblay M. A comparison of direct versus self-report measures for assessing physical activity in adults: a systematic review. Int J Behav Nutr Phys Act. 2008;5:56. doi:10.1186/1479-5868-5-56

8. Sievi NA, Brack T, Brutsche MH, et al. Accelerometer- versus questionnaire-based assessment of physical activity and their changes over time in patients with COPD. Int J Chron Obstruct Pulmon Dis. 2017;12:1113-1118. doi:10.2147/COPD.S130195

9. Watz H, Pitta F, Rochester CL, et al. An official European respiratory society statement on physical activity in COPD. Eur Respir J. 2014;44(6):1521-1537. doi:10.1183/09031936.00046814

10. Gimeno-Santos E, Raste Y, Demeyer H, et al. The PROactive instruments to measure physical activity in patients with chronic obstructive pulmonary disease. Eur Respir J. 2015;46(4):988-1000. doi:10.1183/09031936.00183014

11. Welcome to the International Organisation of La Francophonie's official. Available from: https://www.francophonie.org/Welcome-tothe-International.html. Accessed August 30, 2019.

12. van Gemert F, Kirenga B, Chavannes N, et al. Prevalence of chronic obstructive pulmonary disease and associated risk factors in Uganda (FRESH AIR Uganda): a prospective cross-sectional observational study. Lancet Glob Health. 2015;3(1):e44-51. doi:10.1016/S2214109X(14)70337-7

13. Vuillemin A, Speyer E, Simon C, Ainsworth B, Paineau D. Critical review of the physical activity questionnaires directed at the French population and development perspectives. Cah Nutr Diététique. 2012;47(5):234-241. doi:10.1016/j.cnd.2012.04.002

14. Berthouze SE, Minaire PM, Chatard JC, Boutet C, Castells J, Lacour JR. A new tool for evaluating energy expenditure: the "QAPSE" development and validation. Med Sci Sports Exerc. 1993;25(12):1405-1414. doi:10.1249/00005768-199312000-00015

15. Robert H, Casillas JM, Iskandar M, et al. The dijon physical activity score: reproducibility and correlation with exercise testing in healthy elderly subjects. Ann Readaptation Med Phys Rev Sci Soc Francaise Reeducation Fonct Readaptation Med Phys. 2004;47(8):546-554. doi:10.1016/j.annrmp.2004.03.005

16. de Souto Barreto P, Ferrandez A-M, Saliba-Serre. B. Validation of the QAPPA, a new tool for assessing physical activity among French-speaking elderly. Sci Sports. 2011;26(1):11-18. doi:10.1016/ j.scispo.2010.09.006

17. Vuillemin A, Guillemin F, Denis G, Huot J, Jeandel C. A computer-assisted assessment of lifetime physical activity: reliability and validity of the QUANTAP software. Rev Epidemiol Sante Publique. 2000;48(2):157-167. 
18. Vol S, Bedouet M, Gusto G, et al. Evaluating physical activity: the AQAP questionnaire and its interpretation software. Ann Phys Rehabil Med. 2011;54(8):478-495. doi:10.1016/j.rehab.2011.09.001

19. Vuillemin A, Oppert JM, Guillemin F, et al. Self-administered questionnaire compared with interview to assess past-year physical activity. Med Sci Sports Exerc. 2000;32(6):1119-1124. doi:10.1097/ 00005768-200006000-00013

20. Craig CL, Marshall AL, Sjöström M, et al. International physical activity questionnaire: 12-country reliability and validity. Med Sci Sports Exerc. 2003;35(8):1381-1395. doi:10.1249/01.MSS.00 00078924.61453.FB

21. Crinière $\mathrm{L}$, Lhommet $\mathrm{C}$, Caille $\mathrm{A}$, et al. Reproducibility and validity of the French version of the long international physical activity questionnaire in patients with type 2 diabetes. $J$ Phys Act Health. 2011;8(6):858-865. doi:10.1123/jpah.8.6.858

22. Aguilaniu B, Gonzalez-Bermejo J, Regnault A, et al. Disability related to COPD tool (DIRECT): towards an assessment of COPD-related disability in routine practice. Int $J$ Chron Obstruct Pulmon Dis. 2011;6:387-398. doi:10.2147/COPD.S20007

23. Balish SM, Dechman G, Hernandez P, et al. The relationship between weather and objectively measured physical activity among individuals with COPD. J Cardiopulm Rehabil Prev. 2017;37(6):445-449. doi:10.1097/HCR.0000000000000244

24. Furlanetto KC, Demeyer H, Sant'anna T, et al. Physical activity of patients with COPD from regions with different climatic variations. COPD. 2017;14(3):276-283. doi:10.1080/15412555.2017.1303039

25. Wan ES, Kantorowski A, Homsy D, et al. Promoting physical activity in COPD: insights from a randomized trial of a web-based intervention and pedometer use. Respir Med. 2017;130:102-110. doi:10.1016/j.rmed.2017.07.057

26. Alahmari AD, Mackay AJ, Patel ARC, et al. Influence of weather and atmospheric pollution on physical activity in patients with COPD. Respir Res. 2015;16:71. doi:10.1186/s12931-015-0229-z

27. Beaton DE, Bombardier C, Guillemin F, Ferraz MB. Guidelines for the process of cross-cultural adaptation of self-report measures. Spine. 2000;25(24):3186-3191. doi:10.1097/00007632-20001215000014

28. FFAAIR. Available from: http://bpco.ffaair.org/. Accessed August 30, 2019.

29. French Jardé's law. Available from: https://www.legifrance.gouv.fr/ eli/decret/2016/11/16/AFSP1621392D/jo/texte. Accessed August 30, 2019.

30. Baecke JA, Burema J, Frijters JE. A short questionnaire for the measurement of habitual physical activity in epidemiological studies. Am J Clin Nutr. 1982;36(5):936-942. doi:10.1093/ajcn/36. 5.936
31. Bigard AX, Duforez F, Portero P, Guezennec CY. Assessment of physical activity by questionnaire: validity of the Baecke questionnaire. Sci Sports. 1992;7(4):215-221. doi:10.1016/S07651597(05)80093-0

32. Voorrips LE, Ravelli AC, Dongelmans PC, Deurenberg P, Van Staveren WA. A physical activity questionnaire for the elderly. Med Sci Sports Exerc. 1991;23(8):974-979. doi:10.1249/00005768199108000-00015

33. Kriska AM, Knowler WC, LaPorte RE, et al. Development of questionnaire to examine relationship of physical activity and diabetes in Pima Indians. Diabetes Care. 1990;13(4):401-411. doi:10.2337/ diacare.13.4.401

34. Vilaró J, Gimeno E, Sánchez Férez N, et al. Daily living activity in chronic obstructive pulmonary disease: validation of the Spanish version and comparative analysis of 2 questionnaires. Med Clin (Barc). 2007;129(9):326-332. doi:10.1157/13109543

35. Parada A, Klaassen J, Lisboa C, Saldías F, Mendoza L, Díaz O. Reduction of physical activity in patients with chronic obstructive pulmonary disease. Rev Med Chil. 2011;139(12):1562-1572. [doi:/ S0034-98872011001200005]. doi:10.4067/S0034-98872011001200 005

36. Gouzi F, Préfaut C, Abdellaoui A, et al. Evidence of an early physical activity reduction in chronic obstructive pulmonary disease patients. Arch Phys Med Rehabil. 2011;92(10):1611-1617.e2. doi:10.1016/j. apmr.2011.05.012

37. État des lieux de l'activité physique et de la sédentarité en France. Available from: http:/www.onaps.fr/Etudes-de-l-onaps/les-etudes-de -1-onaps/etats-des-lieux/etat-des-lieux-de-l-activite-physique-et-de-lasedentarite-en-france-edition-2017/. Accessed August 30, 2019.

38. Bauman A, Smith B, Stoker L, Bellew B, Booth M. Geographical influences upon physical activity participation: evidence of a "coastal effect.”. Aust N Z J Public Health. 1999;23(3):322-324. doi:10.1111/ j.1467-842X.1999.tb01265.x

39. Tucker P, Gilliland J. The effect of season and weather on physical activity: a systematic review. Public Health. 2007;121(12):909-922. doi:10.1016/j.puhe.2007.04.009

40. Watz H, Troosters T, Beeh KM, et al. ACTIVATE: the effect of aclidinium/formoterol on hyperinflation, exercise capacity, and physical activity in patients with COPD. Int J Chron Obstruct Pulmon Dis. 2017;12:2545-2558. doi:10.2147/COPD.S143488

41. Troosters T, Bourbeau J, Maltais F, et al. Enhancing exercise tolerance and physical activity in COPD with combined pharmacological and non-pharmacological interventions: PHYSACTO randomised, placebo-controlled study design. BMJ Open. 2016;6(4):e010106. doi:10.1136/bmjopen-2015-010106

\section{Publish your work in this journal}

The International Journal of COPD is an international, peer-reviewed journal of therapeutics and pharmacology focusing on concise rapid reporting of clinical studies and reviews in COPD. Special focus is given to the pathophysiological processes underlying the disease, intervention programs, patient focused education, and self management protocols. This journal is indexed on PubMed Central, MedLine and CAS. The manuscript management system is completely online and includes a very quick and fair peer-review system, which is all easy to use. Visit http://www.dovepress.com/testimonials.php to read real quotes from published authors. 